\title{
Forensic geo-archaeology in Italy: Materials for a standardisation
}

\author{
Pier Matteo Barone ${ }^{1,2, *}$, Rosa Maria Di Maggio², Carlotta Ferrara ${ }^{2,3}$ \\ ${ }^{1}$ Archaeology and Classics Program, The American University of Rome, Via P. Roselli, 4 - 00153 Rome, Italy \\ ${ }^{2}$ Geoscienze Forensi Italia ${ }^{\circledR}$, Forensic Geoscience Italy Team, Rome, Italy. \\ ${ }^{3}$ Department of Mathematics and Physics, University of Roma Tre, Via della Vasca Navale, 84 - 00146 Rome, Italy
}

Email address:

p.barone@aur.edu (P. M. Barone), rosamaria.dimaggio@gmail.com (R. M. Di Maggio), ferrara@fis.uniroma3.it (C. Ferrara)

\section{To cite this article:}

Pier Matteo Barone, Rosa Maria Di Maggio, Carlotta Ferrara. Forensic Geo-Archaeology in Italy: Materials for a Standardisation. International Journal of Archaeology. Special Issue: Archaeological Sciences. Vol. 3, No. 1-1, 2015, pp. 45-56.

doi: 10.11648/j.ija.s.2015030101.16

\begin{abstract}
The so-called 'CSI effect' was recently observed in the Italian judicial system. The reason for the increase in instances of this effect is the lack of a standard geo-archaeological procedure in conducting a forensic investigation. To avoid the harmful consequences of this lack of standardisation, it is necessary to develop a robust geo-archaeological protocol for use during every crime scene investigation.
\end{abstract}

Keywords: Forensic Archaeology, Forensic Geophysics, Forensic Geology, CSI Effect, International Protocol

\section{Introduction}

As expert witnesses, scientists can greatly aid judges and juries by explaining technical matters in easily comprehensible terms. However, when expert testimony is based on mere conjecture or speculation or poor methodology, it can mislead the jury. Ideally, the settling of disputes that involve some scientific or technical information should be no different than settling other disputes between parties. However, not all parties, juries, lawyers and judges are knowledgeable about the issues before them, particularly about science and scientific methods. Even judges are often completely ignorant of such matters. Recently (starting with the Fred West case), an approach involving scientific research specialists has been used in international courtrooms to bring felons to justice through the use of geo-archaeology [1] and [2].

Unfortunately, this approach is very rare in Italy for both investigations and in the courtroom. The question therefore raised is whether Italian investigators and courts wish to obtain the best scientific information from a forensic geo-archaeological expert. How can a geo-archaeological expert clearly present forensic results? The presentation of geo-archaeological evidence to a court must take into account the non-expert nature of the judges, prosecutors, attorneys, and juries and avoid unduly influencing them.

There is an existential risk to courts from the so-called 'CSI effect'. This international effect suggests that the television program and its spin-offs, which wildly exaggerate and glorify forensic science, affect the public and courtroom trials either by (a) burdening the prosecution by creating greater expectations about forensic science than can be delivered or (b) burdening the defence by creating exaggerated faith in the capabilities and reliability of the forensic sciences. This phenomenon has spread from the USA, and now it is also very common in Europe (particularly in the UK) [3]-[5]. Italy is surely not immune to its dissemination, not only in the courtroom but also in popular culture [6].

For these reasons, this paper presents a sort of geo-archaeological protocol to standardise both crime investigations and expert affidavits in the courtroom.

\section{The 'CSI Effect' and Its Implications}

\subsection{Crime Scene Instigation}

Television's diet of forensic fantasy projects the image that all cases are solvable by highly technical science, and if you offer less than that, it is viewed as reasonable doubt. The 'CSI effect' is a term that came into use in approximately 2002, when the TV show Crime Scene Investigation (CSI) started to become extremely popular [7].

CSI's success resulted in the production of many similar shows; in turn, the "CSI effect" has also been associated with 
other US TV crime shows, including Bones, Cold Case, Criminal Minds, Crossing Jordan, NCIS, Numb3rs, etc., making the effect even more relevant. Later, the phenomenon arrived in Europe and began creating the same syndrome in both courtrooms and on TV (e.g., Sherlock and Hinterland in the UK and RIS: Delitti Imperfetti in Italy).

The literature about this effect has been consistent in the USA, where many attorneys, judges, and journalists have claimed that watching television programs such as CSI has caused jurors to wrongfully acquit guilty defendants when no scientific evidence was presented. Consequently, the mass media began to notice these complaints [8].

The literature identifies six specific effects attributed to CSI by various criminal justice observers. The purported 'effects' include: (i) the 'strong prosecutor's effect', whereby jurors wrongly acquit defendants based on a lack of forensic evidence; (ii) the 'weak prosecutor's effect', which suggests that prosecutors must take pre-emptive steps to divert juries from relying on expectations derived from viewing CSI-type shows; (iii) 'the defendant's effect', whereby convictions are seen as more likely because of positive portrayals of forensic work in media outlets; (iv) the 'producers' effect', which claims that CSI-type programs perform a public service by producing better-informed jurors; (v) the 'professor's version', which accounts for a purported surge of interest in forensic science among students; and (vi) the 'police chief's version', which suggests that these TV programs transmit information to criminals about how to avoid detection [4].

In Italy, the constant development of forensic science and technology and the parallel excessive thirst for justice (with the help of the media) sometimes hampers investigations. Making life's pains and tragedies spectacular and accessible to everyone can create the paradox of a person as a killer on the first day, a loving partner on the second day, crazy on the third day, and innocent on the fourth day (and not necessarily in that order) [9].

"But they do it on TV!" This exclamation is very frequently based on impressions derived from all of these TV dramas. The public's introduction to forensic science has created an overlap between TV and reality. Taking into account the intrinsic differences in legal systems, the victims of the CSI effect are often members of juries who remember the fast and effective scientific methods used on TV shows and do not hesitate to ask for limitless scientific evidence, even if it is completely useless and/or detrimental.

\subsection{Crime Scene Instructions}

The more sophisticated CSI-type television story lines become, the better equipped criminals will be. For this reason, it has become necessary that everyone involved in a forensic investigation must be thoroughly prepared and know every possible procedure. However, what happens if these procedures and guidelines are not clear, or, in the worst case, are not complied with?

One of the positive results of the 'CSI effect' is showing that US police follow an inflexible protocol during forensic investigations.
Such procedures should be normal for all law enforcement agencies around the world, but unfortunately, they are not. The following paragraphs explain the situation in Italy and attempt to provide guidance for the creation of a standard protocol for forensic investigations in that country [5].

If there is a general procedure to follow for Italian Police or Carabinieri arriving on a crime scene, nothing has been explicitly defined in terms of what is necessary for searching, locating, or excavating a crime scene. This lack of standards creates several obstacles to concluding an investigation and, consequently, to bringing a culprit to justice.

As shown in Table 1, Italy's guidelines for a crime scene are very similar to the Anglo-Saxon procedures.

Table 1. Crime Scene Procedures

\begin{tabular}{|c|c|c|c|}
\hline \multicolumn{2}{|c|}{ Stage } & \multicolumn{2}{|c|}{ Action } \\
\hline \multirow{5}{*}{ A } & \multirow{5}{*}{$\begin{array}{l}\text { Arriving at the } \\
\text { CS }\end{array}$} & 1 & Receipt of information; \\
\hline & & 2 & Safety procedures; \\
\hline & & 3 & Emergency care; \\
\hline & & 4 & Secure and control people; \\
\hline & & 5 & Establish boundaries and protection; \\
\hline \multirow{4}{*}{ B } & \multirow{4}{*}{$\begin{array}{l}\text { Evaluation of the } \\
\text { Scene }\end{array}$} & 6 & Establish a command post. \\
\hline & & 1 & Conduct scene assessment; \\
\hline & & 2 & Scene 'walk-through'; \\
\hline & & 3 & Note-taking. \\
\hline \multirow{4}{*}{$\mathrm{C}$} & & 1 & Determine the team composition; \\
\hline & & 2 & Ensure contamination control; \\
\hline & Processing the & 3 & Documentation; \\
\hline & Scene & 4 & Collection of evidence; \\
\hline \multirow{3}{*}{$\mathrm{D}$} & & 5 & $\begin{array}{l}\text { Collect, inventory, package, and submit } \\
\text { evidence. }\end{array}$ \\
\hline & Completing the & 1 & Establish the CS debriefing team; \\
\hline & CSI & 2 & Perform final survey. \\
\hline
\end{tabular}

Briefly, these procedures consist of the following steps. Upon arrival at a crime scene, the crime scene investigator makes contact with either the detective/officer who requested the crime scene processing services or with the detective/officer assigned to oversee or manage the crime scene.

Each crime scene investigation is unique, and as such, the establishment of a clear and direct method of communicating crime scene information is required.

Crime scene investigators discuss with the detective or officer in charge of the crime scene information regarding the type of investigation that is under way. Any relevant information regarding the processing of the scene and any specific scene-processing directions or evidence-collection requirements should be made known prior to scene entry [10].

In any crime scene investigation, new or additional information may be developed from outside the scene by the investigating agency. When new or additional information is developed concerning the crime scene, the agency should communicate that information to the crime scene investigator. This new or additional information may cause the crime scene investigator to make changes in scene processing such as expanding to other areas, examining additional items of evidence or even narrowing the scope of the scene and the items of evidence.

Crime scene investigators may develop additional 
information while processing a scene that may support the agency's theory or may be in conflict with statements made by individuals involved in the investigation. In either case, the crime scene investigator advises the detective or officer in charge of the crime scene of the findings so the agency can proceed with its investigation.

A preliminary survey or walk-through of the crime scene with the detective or officer in charge should take place after the exchange of information. The investigator establishes a path to enter and exit the scene, avoiding the pathway used by the suspect, if possible, and preserving the scene from possible contamination.

Trace evidence is any material such as hairs, fibres, glass, soil, paint, etc. found at a crime scene on a person or object. Trace evidence may be used to associate an individual(s) with a crime scene or another individual.

Crime scene investigators should be trained to recognise trace evidence, understand its potential value, and collect and preserve any samples and control samples. When encountering notable items of trace evidence, the items should be documented and collected immediately.

Depending on the conditions at the scene and the stability of the items of evidence (the investigators should have the correct equipment available to search for and collect any trace evidence), any additional items should also be documented and collected [10].

Crime scene investigators may search a crime scene, other locations associated with a crime scene or individuals for suspected biological evidence (i.e., blood, semen, spit).

When suspected biological evidence is identified, a sample or the entire item should be collected for biological analysis. When collecting such items, the investigator should make a mark near the area where the sample was found (with a Sharpie or other marker). An arrow, line or circle should be drawn that clearly indicates the location of the substance.

Crime scene photography is one of the most important duties that a crime scene investigator performs. Visual communications are substantiated and verified by quality, concise and accurate photographs of both the scene and the evidence as it is found. Photographs of the scene and the evidence are one of the first procedures performed at a crime scene; it generally occurs after the note-taking process has begun.

Some biological evidence that cannot be easily identified with the naked eye can be observed with chemical enhancement or an alternate light source. Investigators can use chemical enhancements, such as luminol, when examining areas for small amounts of blood. Luminol causes a chemical reaction to occur with blood, resulting in luminescence or a glow. This process must be conducted in darkened areas to observe and document the chemical reaction.

Finally, the crime scene debriefing is the best opportunity for law enforcement personnel and other responders to ensure that a crime scene investigation is complete [10].

Although these procedures are quite well defined, not all of the steps are always correctly followed. Moreover, the real lack of protocols during investigations in Italy is usually exemplified at the very beginning of an investigation (i.e., the preliminary investigation).

The burial of objects (human remains, explosives, weapons, drugs, etc.) may be associated with serious crimes and can lead to difficult locations to search. Such forensic search scenarios are quite common, but little has been published about them to date [11, and the literature therein]. Most documented discoveries are accidental or result from suspect/witness testimony. The difficulty of locating such hidden objects means that a random or chance-based approach is not prudent. A preliminary geo-archaeological investigation to focus the search of a crime scene is fundamental. Italian law enforcement agencies should adopt procedures that start with a remote sensing study of the region of interest to arrive at the correct excavation area of a crime scene after using other non-destructive approaches, such as cadaver dogs. Table 2 illustrates how such a standardisation of CSI guidelines can be summarised.

Table 2. Geo-Archaeological Investigation of a Crime Scene

\begin{tabular}{ll}
\hline Stage & Action \\
\hline & $\cdot$ Remote sensing; \\
& $\cdot$ Geophysics; \\
& $\cdot$ Cadaver dogs; \\
& $\cdot$ Secure and control people; \\
& $\cdot$ Establish boundaries and protection; \\
& $\cdot$ Establish a command post. \\
& $\cdot$ A, B, and C stages in Table 1; \\
& $\cdot$ Archaeology; \\
& $\cdot$ Geology; \\
& $\cdot$ Anthropology; \\
& $\cdot$ Other geosciences. \\
& $\cdot$ D stages in Table 1. \\
\hline
\end{tabular}

The following paragraphs discuss the above-mentioned geo-archaeological approaches and why they are of paramount importance for an exhaustive and comprehensive forensic investigation. These approaches are not new for international forensic teams; however, in Italy, they are not frequently employed.

\section{Geo-Archaeological Procedures during a Crime Investigation}

\subsection{Remote Sensing}

Remote sensing (RS) is the preliminary tool used to better define a crime scene area. This method is important not only because it is non-destructive but also because it becomes possible to choose the best RS option for the particular forensic case [12].

Remote sensing methods are based on making indirect measurements of the surface and beneath a land area. These measurements are interpreted to identify and characterise contrasts due to differences in the physical and/or natural properties of the materials being investigated. Recent developments in remote sensing equipment and computer technology have improved the chances for the successful 
application of these methodologies, particularly for near-surface (0 to 10 metres) applications [13].

Below, we discuss the most relevant RS techniques and provide a general idea of their purpose and importance during forensic investigations.

\subsubsection{Satellite Imagery and Aerial Photography}

The use of satellite imagery as forensic evidence provides a new application for space technology. The use of space science and its application through satellite imagery can be used to detect mass graves during or after genocide, track troop movements, observe government and opposition forces' activities, and identify human rights abuses such as the deliberate displacement of populations due to arson, border infringements, etc.

Currently, everyone has the ability to use space imagery to settle legal disputes, from homeowners disputing garden boundaries to businesses fighting vehicle theft. Insurers might find it useful to investigate fraud, and government councils can use the technology to tackle environmental assaults such as waste incineration or illegal logging and quarrying. Soon, the use of this technology will not cost much more than an Internet connection.

It might seem simple for someone to use commercial online databases of images to obtain evidence to support forensic cases, but it is not. Finding the right pictures means trawling through huge databases of historical satellite data, and lawsuits involving such approaches frequently fail [14].

Digital images contain an automatic date and time marker embedded within the image file. This metadata contains information about the image file, including items such as the date and time the image was created, the camera and lens used, the focal length, the aperture and shutter speed, and the ISO and GPS position if the camera has the ability to connect to a GPS receiver. This metadata provides a secure means to verify and authenticate an image.

In addition to satellite images, it can also be useful to use aerial photos. Such photos can be in colour or black and white. Colour is normally used for oblique, non-scalable images, while black and white is used for high-resolution images that can be scaled and used for accurate three-dimensional mapping (photogrammetry). This mapping can be presented in a digital form for use in a computer drafting program (CAD) or as a hard copy map showing lines of equal elevation (contours) and spot elevations.

Both satellite and aerial images can provide extensive information about what may be buried in the soil. At the outset, features not visible on the ground are often revealed at altitude. For example, the subtle depressed areas of clandestine pits can be exposed in aerial photographs in early morning or late afternoon when shadows are longest.

Moreover, crop-marks show as differential growth in arable crops caused by the presence of sub-surface forensic features. Sometimes, such features are so clear that they can be observed from the ground or from high buildings or hillsides. For this reason, use of the NDVI (Normalised Difference Vegetation Index) and a 'field-walking' survey can be fundamental [15].

Soil in a buried ditch or pit is still likely to hold some moisture even if it is now under a layer of uniform, ploughed soil. When crops such as barley or wheat grow, their roots find this moisture. The stalks that are rooted in such moisture-holding soil grow slightly quicker and taller than the rest of the crop. Sometimes crop-marks extend over many square miles, and entire multi-period landscapes of super-imposed features ('palimpsests') are visible.

Another search technique involving aerial photography involves comparing historical aerial images in an attempt to discover features placed over buried evidence to conceal it [1].

During an investigation, aerial photographs can serve as interview tools to help witnesses describe locations involved in an incident or to gauge a subject's reaction to certain locations at a crime scene.

Technologically, unmanned aerial vehicles, (UAVs), or "drones", are increasingly used to acquire these types of images. Small portable UAVs, with appropriate air space clearances when needed, can be hovered over outdoor and even indoor crime scenes to acquire video and still photographs. This additional perspective again enhances the documentation and interpretation of each scene [14].

\subsubsection{LiDAR and Laser Scanner}

Light Detective Ranging (or Light Detection and Ranging/LiDAR) is a technology that is based on aerial remote sensing. It measures distance by illuminating a target with a laser and analysing the reflected light. The main advantage of applying LiDAR to a crime scene is the ability to obtain true-to-scale and non-contact measurement of scenes.

LiDAR has many applications in the field of forensic investigation, including aiding in the planning of field campaigns, mapping features beneath forest canopy, and providing an overview of broad, continuous features that may be indistinguishable on the ground. LiDAR can also provide law enforcement with the ability to create high-resolution digital elevation models (DEMs) of crime scenes that can reveal micro-elevations that are otherwise hidden by vegetation. LiDAR-derived products can be easily integrated into a Geographic Information System (GIS) for analysis and interpretation [16].

Features that cannot be distinguished on the ground or through aerial photography can be identified by overlaying hill shades of DEMs created with artificial illumination from various angles. With LiDAR, the ability to produce high-resolution datasets quickly and relatively cheaply can be an advantage. Beyond its efficiency, its ability to penetrate forest canopy has led to the discovery of features that are not distinguishable through traditional geo-spatial methods and that can be difficult to reach through field surveys.

The intensity of the returned signal can be used to detect features buried under flat vegetated surfaces such as fields, especially when mapping using the infrared spectrum. The presence of these features affects plant growth and therefore 
the amount of infrared light reflected back (the so-called NIR, Near-InfraRed analysis).

Additionally, laser scanning uses light properties, but it has a more terrestrial aspect than the LiDAR. It allows for direct field scanning of an object that produces a very precise and accurate three-dimensional digital image from which accurate measurements can be taken. This technology is very effective for analysing physical structures such as buildings, bridges, dams, slopes and other man-made features where a failure has or might occur.

Some applications of 3D laser technologies to forensic science have been proposed. In bloodstain analysis, 3D laser technologies provide a useful way to analyse the number and position of bloodstains; the vertical component is determined more precisely than using conventional methods. It is possible to create a virtual crime scene for reconstruction based on 3D laser technologies (such as 3D documentation, data merging and animation). Such a created virtual crime scene can help investigators understand what happened during a crime. It is also possible to conduct measurements on collected 3D models to obtain more information than from 2D data. Such models also provide the ability to reconstruct missing elements from partial evidence [17].

3D Laser Surveying is now becoming a popular forensic technology that was not available even five years ago that can be used to show data in court. This technology represents the most advanced way to collect crime scene and civil accident data and has been used in many courts across Italy. This technology is currently used in all types of civil and criminal litigation, including insurance cases where a catastrophe or arson has taken place, to bring the scene to the courtroom and show judges and juries scientifically, graphically and intuitively what the environment in which a civil or criminal incident looked like. It also allows for permanent 3D archives of the subject area.

\subsubsection{Thermal Images}

Thermal imaging or infrared thermography is a non-destructive maintenance method that uses infrared cameras to measure the amount of thermal radiation emitted by objects, which is then converted to temperature readings. Infrared images are normally colourised so that objects that emit more thermal radiation than others will appear as brighter colours (yellow, red, and white). Cooler objects appear in darker blue, purple, or green colours. Although thermal imaging normally detects only surface temperatures, infrared signatures often indicate temperatures inside structures [18].

Thermal imaging law enforcement applications can increase an officer's vision and effectiveness, whether pursuing a fugitive, a lost boater, a buried body, or evidence at an accident scene.

Thermal imaging also makes life easier in many of the less stressful but equally demanding areas of police work. Accident scene skid marks reveal many additional clues under infrared study. Hidden compartments in vehicles, stashes in walls, disturbed spots in the dirt - thermal imaging spots them even when the naked eye cannot.

Frequently, searchers equipped with thermal imagers have spotted a lost or missing person and saved a life that might otherwise have been lost. Police officers have spotted and apprehended hidden individuals countless times and usually manage to avoid the danger and risk inherent in such a search or pursuit. The ways in which a thermal imager can contribute to public safety and become an indispensable tool are not always obvious.

Thermal imaging cameras enable searchers to scan a wide area within minutes. They are especially helpful in dense landscapes or in dark and perhaps hard-to-reach alcoves and hideaways where suspects may try to elude police. The technology has also been employed to search for missing persons inside and outside buildings as well as near bodies of water [19].

Moreover, thermal imaging is also helpful to gather physical evidence that may not be immediately apparent through its use of heat sensors to detect disturbed surfaces or hard-to-see objects. It has even successfully located weapons used in crimes.

\subsection{Geophysics}

Forensic geophysics involves the study, search, localisation and mapping of buried objects or elements beneath the soil or water using geophysics tools for legal purposes. Various geophysical techniques can be used for forensic investigations in which the targets are buried and have different dimensions (from weapons or metallic barrels to human burials and bunkers). Geophysical methods have the potential to aid in the search and recovery of these targets because they can non-destructively and rapidly examine large areas where a suspect, an illegal burial or some other forensic target is hidden in the subsoil (Figure 1). When there is a contrast in physical properties between a target and the material in which it is buried in the subsurface, it is possible to individuate and precisely define the searched object's place of concealment. It is also possible to identify evidence of human occupation or excavation in the soil, both recent and older [1].

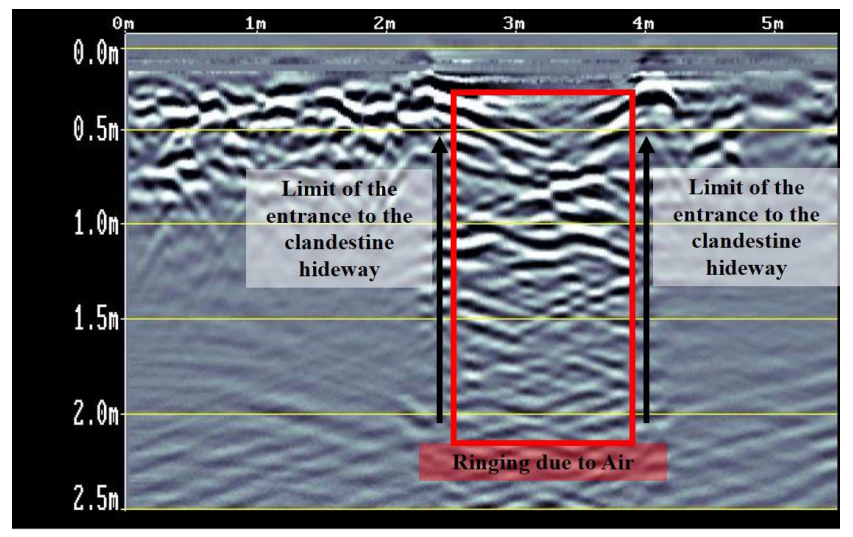

Figure 1. An example of a geophysical technique in a forensic investigation: the use of GPR to detect a clandestine buried hideaway 
Table 3. Comparison of GPR and other geophysical methods

\begin{tabular}{lllll}
\hline $\begin{array}{l}\text { Forensic } \\
\text { Targets }\end{array}$ & GPR & $\begin{array}{l}\text { Electrical } \\
\text { Resistivity }\end{array}$ & Magnetometer & $\begin{array}{l}\text { Metal } \\
\text { Detector }\end{array}$ \\
\hline $\begin{array}{l}\text { Buried bodies } \\
\text { Explosives }\end{array}$ & $* *$ & $*$ & $*$ & \\
$\begin{array}{l}\text { Buried caches } \\
\text { of drugs/money }\end{array}$ & $* *$ & & $*$ & \\
$\begin{array}{l}\text { Guns and } \\
\text { knives }\end{array}$ & $* *$ & $*$ & $*$ (only \\
Artefacts & $* *$ & $*$ & $*$ & metallic) \\
$\begin{array}{l}\text { Tunnels/bunkers } \\
\text { Landfill }\end{array}$ & $* *$ & $*$ & $* *$ & \\
$*$ Recommended & & $* *$ & & \\
$* *$ Recommended + High Resolution & & \\
\hline
\end{tabular}

As shown in Figure 1, Ground Penetrating Radar (GPR) is one of the most useful geophysical tools available to investigate targets beneath the soil or behind a wall. A GPR unit essentially produces a pulsed electromagnetic wave that travels through the ground at a velocity controlled by the electromagnetic properties of the investigated material [20].

Differences in relative permittivity (dielectric constant) or electrical conductivity resulting from changes in soil type or groundwater chemistry result in the waves being reflected. The signals reflected from subsurface interfaces or buried/hidden objects are received by the same antenna used for transmission, providing real-time results.

GPR detects areas of disturbed soil and non-metallic objects that are nearly undetectable using other subsurface investigation tools. Table 3 shows how GPR complements the most commonly used subsurface investigation tools.

The portability and flexibility of the equipment, as well as the real-time visualisation, offers an excellent solution for various applications where other methods may fail.

GPR can assist law enforcement and crime scene investigators in locating evidence behind brick or concrete walls, under wooden floors or in hidden compartments.

Moreover, GPR can provide powerful insight to forensics specialists conducting detailed subsurface site investigations. GPR locates bodies, buried caches, weapons or tunnels, and it can help investigators to rule out suspect areas in minutes.

GPR is a strong investigative tool. The common sense approach for an investigating group is to use all of the tools available, but understanding where and when a particular approach is most cost-effective comes with experience.

GPR is the primary geophysical technique, and it is extremely useful for forensics investigations, particularly regarding a buried victim/target location. GPR's key benefits for forensic site investigations are that it is compact, intuitive, fast, user-friendly, portable and rugged. Moreover, locating and marking buried targets in real time provides the rapid and immediate identification of zones of interest, and grid mapping simplifies data analysis and reduces false alarms. GPR is a very useful method, but those using it must know the proper principles and procedures to obtain the best results [21, and the literature therein].

\section{3. $\mathrm{K9}$}

A vital aspect of a forensic investigation may be to detect and locate specific people or substances of interest, ranging from illegal drugs to missing people. Sophisticated detection equipment does exist; however, this technology can often be expensive, have unsuitable portability, and may even prove useless when searching vast areas. Fortunately for investigators, there is an ideal tool available [22].

Dogs, commonly known as $\mathrm{K} 9 \mathrm{~s}$ by law enforcement professionals due to homophony with the word 'canine', have played an important role in legal investigations for decades because of their keen sense of smell. The average human being's nose has roughly five million sensitive cells, which appears to be a large number until it is compared with the 200 million cells in the average dog's nose. Further increasing a canine's sense of smell is an organ in the roof of the mouth that is not present in humans. This organ essentially allows a dog to 'taste' a smell, thus strengthening its ability to detect odours. Canines detect odours directly from their source or from residual scents, which are odours that persist in an area after the original source is no longer present.

Obviously, the air is full of a variety of different odours, many of which are powerfully clear to a dog. Fortunately, they are able to distinguish between different odours, even when one smell overpowers another, and trace a specific scent to its source.

The police commonly train canines to detect the presence of illicit substances because they are capable of locating even the tiniest trace of a drug. Dogs are frequently used on country borders and in train stations, airports, workplaces, and even schools to allow police to locate individuals who are carrying illegal substances. A dog may be moved near pieces of luggage or groups of people and observed for a reaction if he or she picks up on an odour of interest. An average stop and search conducted by officers may yield nothing, especially if the subject has hidden drugs somewhere on his person. However, properly trained canines are usually able to detect the scent of illegal narcotics, regardless of where the suspect has concealed them.

Perhaps more often in recent years due to the increased attention to terrorism, canines have also been trained in the detection of explosive materials. Dogs can be trained to detect the odours of specific substances such as sulphur, nitro-glycerine, or any other compound commonly used in the production of gunpowder and explosive devices. Such specially trained dogs can be used in airports to detect or at least deter terrorism or in the homes of suspected bomb-makers to identify the presence of these substances on work surfaces and in storage areas. In these scenarios, it is particularly vital that the canine is trained not to touch the substances or devices it locates because many types of bombs can potentially explode if touched.

'Cadaver dogs' are specially trained to follow the scent of decomposing flesh to locate the bodies of deceased human beings. Whether a cadaver is on the surface, buried 
underground or even underwater, a dog's nose is powerful enough to pick up the scent and trace it back to its source. Cadaver dogs can not only locate actual human remains but also the location where a corpse or body parts may have previously been stored by tracking down residual scents. Depending on the use of the cadaver dog, it can be trained to detect specific decomposition odours. For example, some cadaver dogs may be trained to detect odours associated with the early stages of decomposition, whereas others may be trained to locate older remains. Some dogs are specifically trained to detect dead bodies underwater, with the canine situated on the shoreline or in a boat. A more recent concept is detection dogs for historical human remains to locate historical or archaeological graves [23].

Similar to cadaver dogs, search and rescue canines are also specifically trained to locate human beings. However, in this instance, they are searching for living individuals - usually missing people, individuals lost in the wilderness, and those trapped during mass disasters. For example, trained dogs are used in the case of an earthquake where numerous people may be trapped inside crushed buildings or other structures. The dogs follow the scent of each person so that they can be located and rescued.

\subsection{Archaeology}

Forensic archaeology is a scientific discipline that uses archaeological theory and methodology in a legal context. It combines archaeological, taphonomical and criminalistic knowledge to localise, document and interpret archaeo-pedological, archaeo-ecological and osteological finds and patterns at a (possible) place of incidence or a crime scene.

The principal aim of forensic archaeology is to obtain a scientific-based reconstruction of the human and natural activities that occurred on and around a crime scene or place of incidence, especially during the surface recovery of fragmented human remains and related finds and features, a survey for clandestine buried persons or objects, an excavation of clandestine buried persons or objects and related finds and features, the exhumation of persons at regular cemeteries for additional examination and the dating of (buried) skeletonised human remains [24].

Unfortunately, as shown in the publication by [25], the practice of forensic archaeology has scarcely been applied at most European crime scenes, and the excavation and recovery of human remains in forensic contexts in Europe has mostly been conducted by police officers with no archaeological training, forensic anthropologists, or forensic pathologists.

A forensic archaeologist's first involvement in a case is to help the police locate the site of a body and/or a victim's personal items. Then, the forensic archaeologist starts to dig using the tools and expertise required for a stratigraphic excavation (Figure 2). The dig must be conducted meticulously and not arbitrarily (i.e., by arriving directly at the buried target using bulldozers or similar equipment) using the proper tools. The archaeologist must record and preserve anything found at every stage and depth (for example, paint flakes, hair, clothing or DNA) because it may be vital evidence [1].

Forensic archaeologists can date items found in grave sites, including bones, using two different types of techniques: absolute and relative. An example of absolute chronology is carbon dating, which can determine whether a grave site is recent or ancient. Conversely, stratigraphy and the examination of every piece of evidence found in removed soil is an example of relative chronology, where, for example, a buried element with a date (e.g., a milk bottle or a receipt) above or below the forensic target can provide information about the time of burial. Additionally, evidence from forensic archaeologists regarding how materials degrade or decompose over time and in specific conditions can be important because it can help determine, for example, how long a body has been buried by the state of the clothes or the surrounding soil or how long stolen goods have been buried by the subsequent damage to metal and other materials [24].

Moreover, forensic archaeologists often excavate mass graves to provide evidence for war crimes trials, and they collect and collate human remains and personal effects at scenes of mass fatalities such as bomb or gas explosions or plane crashes.

Forensic archaeologists may have to give evidence in court as an expert witness, and they must be able to communicate complex issues to a lay audience.

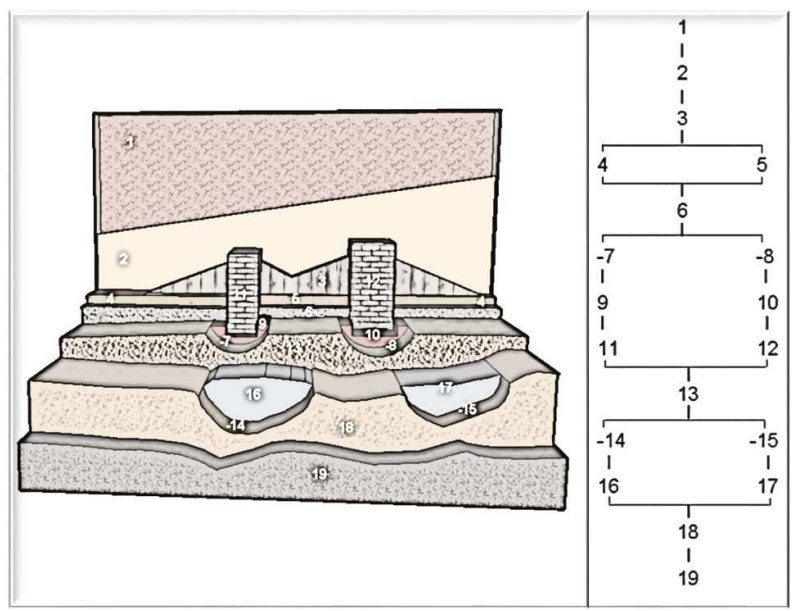

Figure 2. An example of an archaeological stratigraphy with the chronological sequence of both the natural and artificial layers

\subsection{Geology}

Forensic geology is a large subject that applies the defining principles of the geological sciences to the identification and/or evaluation of geological materials related to forensic issues. Forensic geology also applies these principles to define the appropriate geological context of a crime scene.

Forensic pedology is a branch of forensic geology that involves searching, studying and analysing soil traces that are connected to a crime to help a judicial investigation [1]. 
Because soil can be transferred from place to place on movable surfaces (shoes, tyres, clothes, etc.), it can provide important information to connect a person under investigation to a site, or it can shed light on the dynamics of a crime [26] (Figure 3). For example, in a case where the victim of a homicide has been removed from the scene of the crime and taken to another site, soil analysis can provide useful indications to connect the victim, the vehicle by which he/she was transferred, the sites and the suspect. However, soil has a complex system and is comprised of several microscopic components that have formed and developed during its long genesis and evolution. This process depends on a multitude of factors, namely topography, the climate, the typology of its parent rock, tectonics, erosion, the sedimentary environment, anthropogenic activity and the typology of organic substances. Because of this complexity, it is easy to find considerable differences among soil samples even when the soil is considered to be homogenous, to the point that soil components and their reciprocal ratio report variations in small areas. For these reasons, a pedological analysis is an excellent tool to support judicial investigations [1].

There is an enormous diversity of earth surface materials, and the fact that modern techniques are capable of very detailed characterisation and discrimination makes such materials potentially highly useful in a forensic context.

Forensic geological techniques and information can be applied to a wide range of civil law and criminal law issues, including such problems as environmental accidents, construction failures, pollution and, of course, serious crimes such as murder, terrorism, genocide, arson, drug smuggling and rape.

Forensic geological information can also be used for simple 'intelligence' purposes within the framework of an ongoing police investigation or as evidence for presentation in court, depending on the quality of the data and strength of the conclusions that can be drawn. By combining geological information with data obtained from related sub-disciplines, such as forensic botany, useful information about provenance and geographic location can be provided.

This type of approach is sometimes referred to as 'environmental profiling' and is analogous to geographical profiling and psychological profiling undertaken by behavioural scientists.

The importance of geological evidence can be attributed not only to its prevalence at crime scenes and its transferability between the scene and the criminal but also to the fact that soil or sediments are comprised of naturally occurring rocks, minerals, flora, and fauna in addition to anthropogenic components such as glass, paint fragments, and metallic particles with peculiar characteristics and properties [27]. According to Murray, forensic geology began with Sherlock Holmes writer Sir Arthur Conan Doyle [28]. The character Sherlock Holmes claimed to be able to identify where an individual had been by various methods, which included memorising the exposed geology of London to such a degree that detecting certain clays on a person's shoe could give away a location.
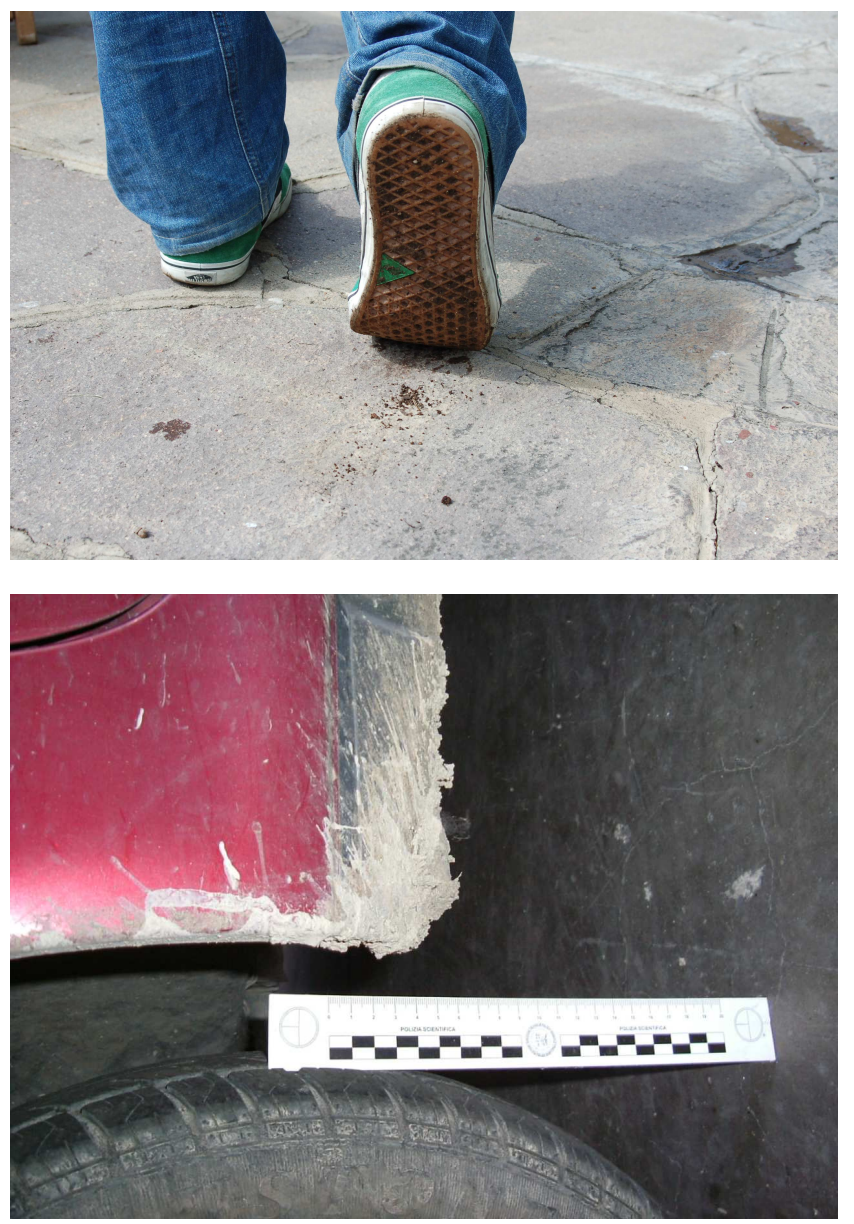

Figure 3. Two examples of soil transfer on a movable surface: shoes (above), and a fender (below)

\subsection{Anthropology}

Anthropology is the study of humankind, culturally and physically, in all times and places. Forensic anthropology is the application of anthropological knowledge and techniques in a legal context. This discipline involves detailed knowledge of osteology (skeletal anatomy and biology) to aid in the identification and determination of the cause of death of skeletal remains, as well as the recovery of remains using archaeological techniques [29, and the literature therein].

The first thing an examining anthropologist must determine is whether a material is bone. A surprising number of other materials can be mistaken for bone at first glance, especially if they are covered with dirt or other substances. Ceramic shards, plastic, wood fragments, rocks, and small bits of concrete can all be mistaken for bones or bone fragments. To ensure that a material is bone, an anthropologist cleans the object and examines it closely, under magnification if necessary.

Once the anthropologist is sure that a material is bone, he or she must determine whether it came from a human or a non-human animal. All mammals share a generalised skeletal template, meaning that they all have the same bones 
in roughly the same locations: a skull, spine (which ends in a tail), ribs (which support the internal organs), and four sets of limb bones. However, the shape of the bones and the way they relate to each other differ between animals. By examining the size, shape, and structure of a bone, an anthropologist can determine if it is human.

Once a case involves human bone, the investigator must identify which bones (or 'elements') are present and which are absent. Most anthropologists start this process by placing the elements on a table as they would be organised in a living person, known as the "anatomical position". This approach serves several purposes. First, it creates an informal visual inventory that allows any missing elements to be identified quickly. Additionally, it allows the analyst to work systematically through the entire skeleton and perform a detailed inventory and examination of each bone for trauma pathology, or life history traits. Finally, after examining each bone, the analyst can consider the skeleton as a whole and look for inconsistencies among elements or patterns of trauma across multiple elements.

At a recovery site, skeletal inventories are important because they allow searchers and scene responders to know what they might be looking for that they have not already recovered, which ensures that they make as full a recovery as possible. Inventories are also important from a criminal perspective for establishing what elements are or are not present. The absence of certain elements can provide a great deal of information regarding perimortem events, taphonomy, and perpetrator behaviour.

In addition to establishing which elements are present, anthropologists must determine the number of individuals involved. To do this, they look for duplicate elements - for example, two right femora (thigh bones). Investigators also consider the condition and size of the bones. If the elements do not "match", it could suggest more than one individual. When the remains of two or more individuals are mixed together, it is called "comingling". It is the anthropologist's job to address comingling and determine which individuals are represented by which bones, allowing each body to be examined separately [1].

Establishing the number of individuals is very important, especially if the case involves a crime. Multiple individuals may be killed together, or separate victims may be dumped in the same place over a longer period of time. Sometimes perpetrators bury many victims together in a mass grave in an attempt to conceal their behaviour. In all such cases, it is very important to the understanding and resolution of the case that the anthropologist is as accurate as possible about how many victims were involved.

As specialists in the study of human remains, anthropologists are often called upon to distinguish ancient burials and remains from modern deaths of forensic significance.

Anthropologists can often tell the difference between an ancient and a modern skeleton by the context of deposition. This context can include the location, position, and condition of the body, and it can provide clues to the events that led to its burial. Associated material evidence can also suggest the origin of a set of remains. Obviously, remains found with modern clothing, a mobile phone or an mp3 player in a pocket and modern dental work are those of a person who died very recently. However, skeletal remains found in association with cultural objects consistent with local First Nations burial practices are likely to be those of a person buried according to his or her cultural and social heritage and are therefore not of forensic interest.

Anthropologists contribute to the identification of unknown individuals by developing a biological profile: age, sex, stature, and ancestry. In addition, a biological profile includes information that may be particular to that person and no one else, such as diseases or injuries that may have impacted the bone [30].

Skeletal analysis also reveals clues that could suggest how a person died, such as cut marks from a knife and fractures resulting from gunshots or blunt force trauma. The stage of body decomposition in combination with information about environmental conditions can help an anthropologist estimate how long an individual has been dead (the PMI Post-Mortem Interval).

Forensic anthropologists are also trained to examine evidence regarding the circumstances surrounding the death of an individual. Such an examination involves analysing skeletal trauma and differentiating between injuries caused by bullets, sharp objects, blunt objects, or other instruments. Sharp force trauma results when a narrow or pointed object hits a very small area. The stabs, slashes, and cuts typical of sharp force often penetrate deep enough to leave cut marks on the bone. In contrast, blunt force trauma results from a larger implement hitting a much broader area. Blunt force trauma can cause fractures of the arm and leg bones or crush and shatter the flat bones of the skull. Projectile trauma involves great force applied over a very small area. Projectile trauma can involve bullets, arrows, spears, or any other small object delivered at high velocity. The damage caused by projectile trauma can often be used to indicate the direction of the projectile's travel. Other forms of trauma that an anthropologist may find evidence of include strangulation, electrocution, chemical- or heat-related trauma, or explosions.

In addition to the injuries themselves, the patterns of injuries present on a body can be very important to a case. Multiple, severe blunt force injuries over an entire body can suggest a fall from a great height or a car accident. Sharp force injuries to the hands and lower arms are indicative of defensive wounds. The direction of projectile wounds can also be used to support or refute a suspect's story.

Whether it relates to an accident or a crime, the timing of an incident is an important aspect of any investigation. To address the question of elapsed time since death, anthropologists use taphonomy to understand the context and conditions that alter human remains, including all of the biological and non-biological processes that contribute to decomposition, skeletonisation, and depositional changes. Biological factors include human agents, animals, plants, 
insects, and invertebrates. It is common for carnivores to scavenge fresh remains and for rodents to gnaw on dried remains. Plant roots can etch into bone surfaces, and insects and worms can move remains during tunnelling and nest-building. Low soil $\mathrm{pH}$, wind, water, and sand are all capable of causing abrasions on bone surfaces. Repeated freeze and thaw cycles can reduce a bone to fragments, while intense heat and sun can cause the surface of bones to crack and peel away. Using their knowledge of taphonomic processes, anthropologists can estimate the length of time a body has been buried or exposed or determine whether a set of remains has been moved [29, and the literature therein].

Once a biological profile has been created and a potential missing person identified, investigators must try to ensure that unknown remains actually belong to the missing person in question. One of the best methods is to compare antemortem medical records with the evidence presented by the remains. For example, radiographs ("x-rays") taken during life can be compared to radiographs of skeletonised remains. Examiners look for size, shape, and features to determine whether antemortem and post-mortem radiographs represent the same individual. Medical records of individuals with surgical implants such as pacemakers, breast augmentations, surgical steel orthopaedic pins, etc. can be correlated with the presence of similar objects recovered with remains.

\subsection{Other Geosciences}

Promising protocol developments are likely to occur as a result of closer interdisciplinary collaboration between the different forensically related sub-disciplines. For this reason, if the geo-archaeological analysis of a crime scene requires more specialised scrutiny, it is worth communicating with experts in the other geosciences during such procedures.

\subsubsection{Entomology}

Forensic entomology is the use of the insects and their arthropod relatives that inhabit decomposing remains to aid legal investigations. The broad field of forensic entomology is commonly divided into three general areas: medico-legal, urban, and stored product pests.

The medico-legal area focuses on the criminal component of the legal system and addresses the necrophagous- (or carrion-) feeding insects that typically infest human remains.

The urban aspect concerns the insects that affect man and his immediate environment. This area has both criminal and civil components because urban pests feed on both the living and the dead. The damage caused by their mandibles (or mouth parts) as they feed can produce markings and wounds on the skin that can be misinterpreted as prior abuse. Urban pests are of great economic importance, and forensic entomologists sometimes become involved in civil proceedings over monetary damages [31, and the literature therein].

Finally, stored product insects are commonly found in foodstuffs, and a forensic entomologist can serve as an expert witness during both criminal and civil proceedings involving food contamination.

\subsubsection{Botany}

Forensic botany is the application of plant sciences to criminal investigations. A relatively new discipline, forensic botany incorporates several sub-disciplines: palynology (the study of pollens), dendrochronology (the study of tree rings), limnology (the study of aquatic environments), systematics (the classification of plants), ecology (the study of ecosystems), and molecular biology [32, and the literature therein].

Unlike forensic anthropologists, forensic botanists do not normally examine human remains. Their primary role in an investigation is to make connections between evidence and a crime. For example, pollen can be used to connect a suspect to a victim or a crime scene. Pollen is a powder-like substance that is released by plants as part of their reproductive cycle. Because it is produced in large volumes and is easily transported by wind, pollen grains are often found on clothes, hair or skin. If investigators find a rare type of plant near a murder victim, the presence of its pollen on a suspect could place that person at the scene. Even for common plants, each environment has its own unique combination of pollens, and this 'signature' can link an individual or object to a location. Pollen signatures can also indicate that a body has been moved or suggest the type of area where the original crime took place.

\subsubsection{Geochemistry}

Forensic geochemistry is a branch of geology that consists of collecting, analysing and studying crime-related geological samples to help a judicial investigation. Geochemical signatures provide key information about the origin and nature of pollutants, and they can be used to track pollutants through their interaction processes in different environmental matrices (emissions into the air, water and soil).

Forensic geochemistry can be used to reveal environmental crimes such as pollution of groundwater or soils or emissions of harmful substances into the atmosphere. It is also a powerful tool to support traditional investigation methods in cases of violent crimes and thefts [33].

The isotopic composition of geological material (i.e., rock, minerals, groundwater) can be considered its "DNA", which often contains a unique signature. Isotopic analysis has been widely used in geochemistry to identify various sources of material and processes and can provide relevant information to shape the criminal dynamic.

Image analysis has become one of the most valuable tools in the forensic sciences to reveal subtle traces that are not visible to the naked eye but can be highly relevant for a crime reconstruction.

\section{Discussion and Conclusions}

As shown in Table 4 based on the preceding analysis, it is possible to develop standard procedures for a forensic investigation. 
Table 4. A geo-archaeological protocol for a crime scene

\begin{tabular}{lll}
\hline $\begin{array}{l}\text { General } \\
\text { Action }\end{array}$ & Specific Action & Topic \\
\hline \multirow{4}{*}{ Recovery } & Search & Remote sensing, K9, \\
& Discovery & Geophysics, \\
& Excavation & Archaeology, Geology, \\
& Stratigraphy (order of events) & Anthropology, \\
& Collect evidence & Entomology, Botany. \\
& Transfer information & \\
& Biological profile & Geology, \\
& Determine sex, age, and ancestry & Anthropology, \\
Analyse & Calculate stature & Archaeology, Botany, \\
& Trauma and pathology & Entomology \\
& Insects & \\
& Vegetal remains & \\
& Anthropogenic artefacts & Anthropology \\
\hline
\end{tabular}

However, if a geo-archaeological protocol for forensic investigations is to be helpful for law enforcement agencies, another aspect must be highlighted: the role of the geo-archaeological expert.

As depicted in Figure 4, a CS analysis can become a bottleneck in which it is easy to lose information, or it can be a fundamental resource used to solve a case.

\section{THE CRIME SITE ANALYSIS}

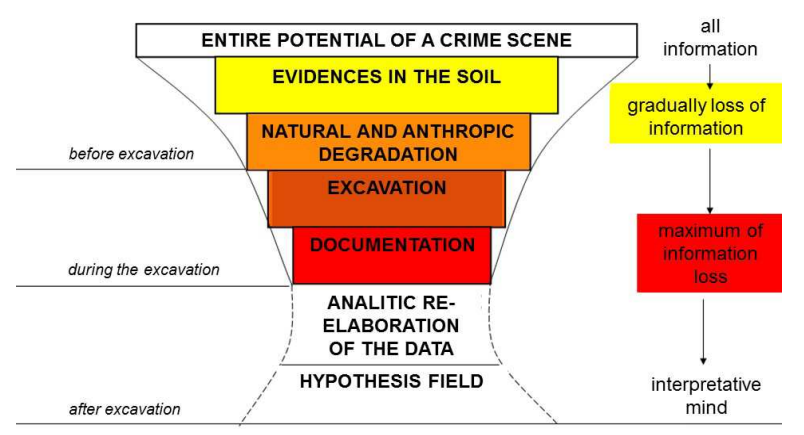

Figure 4. The crime scene analysis diagram

The before/during/after-excavation information must be documented correctly to avoid the partially natural and partially artificial gradual loss of information. However, if the expert involved does not correctly re-elaborate such information, an interpretative mind will not be enough to solve the case.

Moreover, the famous rule 702 [34] states that an expert witness must: i) present sufficient facts and data; ii) reconstruct events based on reliable principles and methods; and 3) reliably apply the principles and methods to the case. In Daubert, the Court had not yet stressed the principle of general acceptance by the scientific community but placed the burden on a judge to determine the admissibility of new evidence based on the judge's critical evaluation of the reliability of the methods and procedures used by an expert. This assessment must be conducted by considering principles such as the possibility of subjecting the theory or scientific technique to empirical analysis to verify or refute it; the existence of a critical review by experts in the field; an indication of the known or potential margin of error; and the existence of standards relating to the use of the technique employed. Since that case, Daubert has become a reference point for the assessment of scientific evidence. Even when the Daubert criteria should not be applicable (such as with a peer-reviewed publication), it is up to judges to evaluate the technical and scientific methodologies used by expert witnesses.

This ruling made judges the custodians of the law and reiterated that they have the last word on the validity of the knowledge presented at trial. Even if a party recognises that it needs science to shed light on particularly complex issues for which a judge does not possess the necessary tools for interpretation, the judge still reserves the right to decide whom to recognise with the title of scientist. Thus, the judge is the peritus peritorum (expert of experts). In fact, in Italy, the judge makes the final decision on the guilt or innocence of the accused and is also responsible for evaluating the reliability of any technical-scientific resources used in the process.

Thus, the presence of a geo-archaeological protocol in Italy can help prevent the risk of the judicial system suffering from the 'CSI effect', as has recently occurred [35].

Indeed, this paper is addressed to Italy, in which forensic investigations have no geo-archaeological protocols or standard procedures, to provide the country's law enforcement agencies with the materials to create a multidisciplinary approach to a crime scene using the correct personnel and the appropriate tools [36].

\section{References}

[1] R.M. Di Maggio, P.M. Barone, E. Pettinelli, E. Mattei, S.E. Lauro, A. Banchelli, "Geologia Forense. Introduzione alle geoscienze applicate alle indagini giudiziarie", Flaccovio editore, 2013, pp. 217-287. ISBN 9788857902333.

[2] P. Goldberg, R.I. Macphail, "Practical and Theoretical Geoarchaeology”, Wiley, 2006, pp. 286-293. DOI: $10.1002 / 9781118688182 . c h 14$

[3] Y.S. Kim, G. Barak, D.E. Shelton, "Examining the "'CSI-effect' in the Cases of Circumstantial Evidence and Eyewitness Testimony: Multivariate and Path Analyses", Journal of Criminal Justice, 37, 5, 2009, pp. 452-460. DOI: 10.1016/j.jcrimjus.2009.07.005

[4] L. Huey, "'I've seen this on CSI': Criminal investigators' perceptions about the management of public expectations in the field", Crime Media Culture, 6, 1, 2010, pp. 49-68. DOI: $10.1177 / 1741659010363045$

[5] E. Bergslien, "Teaching To Avoid the 'CSI Effect'. Keeping the Science in Forensic Science, Journal of Chemical Education, 83, 5, 2006, pp.690-691.

[6] M. Houck, "Effetto CSI: i miti, le realta', i pro e i contro del successo dei telefilm sulle indagini di polizia scientifica", Le Scienze, 457, Settembre 2006.

[7] S.A. Cole and R. Dioso-Villa, "Investigating the 'CSI Effect' effect: media and litigation crisis in criminal law", Stanford Law Review, 61, 6, 2009, pp. 1335-1374. 
[8] D.E. Shelton, “The 'CSI Effect': does it really exist?”, NIJ, 259, 2008, pp. 1-7.

[9] T. R. Tyler, "Viewing CSI and the threshold of guilt: managing truth and justice in reality and fiction", The Yale Law Journal, 115, 2006, pp. 1050-1085.

[10] National Forensic Science Technology Center, "Crime Scene Investigation: a guide for law enforcement”, NFSTC, 2013.

[11] A. Ruffell, J.K. Pringle, S. Forbes, "Search protocols for hidden forensic objects beneath floors and within walls", Forensic Science International, 237, 2014, pp. 137-145. DOI:10.1016/j.forsciint.2013.12.036

[12] G.C., Davenport, "Remote Sensing Applications in Forensic Investigations", Historical Archaeology, 35, 1, 2001, pp. 85-100.

[13] J.K. Lein, "Forensic Remote Sensing", in J.K. Lein (ed.) "Environmental Sensing", Springer 2012, pp. 279-301. DOI: 10.1007/978-1-4614-0143-8_12

[14] G.A. Elmes, G. Roedl, J. Conley, "Forensic GIS: The Role of Geospatial Technologies for Investigating Crime and Providing Evidence", Series: Geotechnologies and the Environment, Vol. 11, 2014. ISBN 978-94-017-8756-7

[15] W.M. Grip, R.W. Grip, R.D. Morrison, "Application of Aerial Photography and Photogrammetry in Environmental Forensic Investigations", Environmental Forensics, 1, 3, 2000, pp. 121-129. DOI: $10.1006 /$ enfo. 2000.0014

[16] W. Che-Yen, C. Hsuan-Hsiao, L. Chao-Kuo, Y. Wen-Chao, “A Study of Applying Light Detection and Ranging (LIDAR) to Crime Scene Documentation", Forensic Science Journal, 12, 1, 2013, pp. 31-46.

[17] R.M. Morgan, P.A. Bull, "Forensic geoscience and crime detection”, Minerva Med. Leg., 127, 2007, pp. 73-89.

[18] R.M. Gradner, "Practical Crime Scene Processing and Investigation”, CRC Press, 2011. ISBN: 978-1439853023

[19] S.L. Morgan, M.L. Myrick, "Rapid Visualization of Biological Fluids at Crime Scenes using Optical Spectroscopy", Final Technical Report, National Institute of Justice Award, 2007, DN-BX-K199

[20] A. Ruffell, J. McKinley, "Geoforensic", 2008, Wiley, 978-0-470-05735-3

[21] J.J. Schultz, M.M. Martin, "Controlled GPR grave research: Comparison of reflection profiles between 500 and $250 \mathrm{MHz}$ antennae", Forensic Science International, 209, 1-3, 2011, 64-69.

[22] S.M. Stejskal, "Death, Decomposition, and Detector Dogs: From Science to Scene", 2012, CRC Press. ISBN: 978-1-4398-7837-8
[23] J.J. Ensminger, "Police and Military Dogs: Criminal Detection, Forensic Evidence, and Judicial Admissibility", 2011, CRC Press. ISBN: 978-1439872390

[24] W.J.M. Groen, N. Marquez-Grant, R. Janaway, "Forensic Archaeology: A Global Perspective", 2015, Wiley, 978-1-118-74598-4

[25] N. Marquez-Grant, S. Litherland, J. Roberts, "European Perspectives and the Role of the Forensic Archaeologist in the UK", in D.C. Dirkmaat, "A Companion to Forensic Anthropology", 2012, Wiley. DOI. 10.1002/9781118255377.ch29

[26] R.M. Di Maggio, M. Maio, and L. Nuccetelli, "Geologia forense", in M. Picozzi and A. Intini A. (eds) "Scienze Forensi: Teoria e Prassi dell'Investigazione Scientifica", Utet, Torino, 2009, pp. 255-266.

[27] P. Magni, R.M. Di Maggio, "Le scienze naturali ad applicazione forense", in R.V.O. Valli (ed.), "Le Indagini scientifiche nel procedimento penale", Giuffrè, Milano, 2013.

[28] R.C. Murray, "Evidence from the Earth. Forensic Geology and Criminal Investigation", Mountain Press Publishing Company, Missoula, Montana, 2004.

[29] D.C. Dirkmaat, "A Companion to Forensic Anthropology", 2012, Wiley. DOI. 10.1002/9781118255377

[30] A. Libal, "Forensic Anthropology", 2014, Mason Crest. ISBN: 9781422289556

[31] D.B. Rivers, G.A. Dahlem, "The Science of Forensic Entomology", 2013, Wiley.

[32] I. Aquila, F. Ausania, C. Di Nunzio, A. Serra, S. Boca, A. Capelli, P. Magni, P. Ricci, "The Role of Forensic Botany in Crime Scene Investigation: Case Report and Review of Literature", Journal of Forensic Sciences, 59, 3, pp. 820-824. DOI: $10.1111 / 1556-4029.12401$

[33] V.T. Jones, P.N. Agostino, "Forensic Geochemistry: The key to accurate site characterizations", in V.T. Jones, P.N. Agostino (eds.) "2001 Petroleum Hydrocarbons and Organic Chemicals in Ground Water: Prevention, Detection, and Remediation Conference", National Ground Water Association, 2001, p. 119-135.

[34] L. Dixon, B. Gill, "Changes in the Standards for Admitting Expert Evidence in Federal Civil Cases Since the Daubert Decision", RAND Institute for Civil Justice, 2002.

[35] C. Poli, C. Brondoni, "Crimini e serie tv - l'omicidio fra piccolo schermo e realtà”, 2013, Narcissus.me. ISBN: 9788868557836

[36] T. Buckles, "Crime Scene Investigation, Criminalistics, and The Law”, 2006, Cengage Learning. ISBN: 978-1401859299 